\title{
Sites of metastasis and association with clinical outcome in advanced stage cancer patients treated with immunotherapy
}

Mehmet Asim Bilen ${ }^{1,2^{*}+}$ D, Julie M. Shabto ${ }^{1,2 \dagger}$, Dylan J. Martini ${ }^{1,2}$, Yuan Liu ${ }^{3}$, Colleen Lewis ${ }^{2}$, Hannah Collins ${ }^{2}$, Mehmet Akce ${ }^{1,2}$, Haydn Kissick ${ }^{2,4}$, Bradley C. Carthon ${ }^{1,2}$, Walid L. Shaib ${ }^{1,2}$, Olatunji B. Alese ${ }^{1,2}$, Conor E. Steuer ${ }^{1,2}$, Christina Wu ${ }^{1,2}$, David H. Lawson ${ }^{1,2}$, Ragini Kudchadkar ${ }^{1,2}$, Viraj A. Master ${ }^{4}$, Bassel El-Rayes ${ }^{1,2}$,

Suresh S. Ramalingam ${ }^{1,2}$, Taofeek K. Owonikoko ${ }^{1,2}$ and R. Donald Harvey ${ }^{1,2,5}$

\begin{abstract}
Background: Selecting the appropriate patients to receive immunotherapy $(\mathrm{IO})$ remains a challenge due to the lack of optimal biomarkers. The presence of liver metastases has been implicated as a poor prognostic factor in patients with metastatic cancer. We investigated the association between sites of metastatic disease and clinical outcomes in patients receiving $\mathrm{IO}$.

Methods: We conducted a retrospective review of 90 patients treated on IO-based phase 1 clinical trials at Winship Cancer Institute of Emory University between 2009 and 2017. Overall survival (OS) and progression-free survival (PFS) were measured from the first dose of $1 \mathrm{O}$ to date of death or hospice referral and clinical or radiographic progression, respectively. Clinical benefit (CB) was defined as a best response of complete response (CR), partial response (PR), or stable disease (SD). Univariate analysis (UVA) and Multivariate analysis (MVA) were carried out using Cox proportional hazard model or logistic regression model. Covariates included age, whether IO is indicated for the patient's histology, ECOG performance status, Royal Marsden Hospital (RMH) risk group, number of metastatic sites, and histology.
\end{abstract}

Results: The median age was 63 years and $53 \%$ of patients were men. The most common histologies were melanoma (33\%) and gastrointestinal cancers (22\%). Most patients (73.3\%) had more than one site of distant metastasis. Sites of metastasis collected were lymph node $(n=58)$, liver $(n=40)$, lung $(n=37)$, bone $(n=24)$, and brain $(n=8)$. Most patients $(80.7 \%)$ were RMH good risk. Most patients $(n=62)$ had received $2+$ prior lines of systemic treatment before receiving $1 \mathrm{O}$ on trial; 27 patients (30.0\%) received prior ICB. Liver metastases were associated with significantly shorter OS (HR: 0.38, Cl: 0.17-0.84, $p=0.017$ ). Patients with liver metastasis also trended towards having shorter PFS (HR: $0.70, \mathrm{Cl}: 0.41-1.19, p=0.188$ ). The median OS was substantially longer for patients without liver metastases (21.9 vs. 8.1 months, $p=0.0048$ ).

Conclusions: Liver metastases may be a poor prognostic factor in patients receiving $1 O$ on phase 1 clinical trials. The presence of liver metastases may warrant consideration in updated prognostic models if these findings are validated in a larger prospective cohort.

Keywords: Immunotherapy, Phase 1 clinical trials, Sites of metastasis, Liver metastasis, Clinical outcomes, Tumor immunology, Tumor microenvironment, Immune checkpoint blockade

\footnotetext{
* Correspondence: mehmet.a.bilen@emory.edu

${ }^{+}$Mehmet Asim Bilen and Julie M. Shabto contributed equally to this work.

${ }^{1}$ Department of Hematology and Medical Oncology, Emory University School of Medicine, Atlanta, GA, USA

${ }^{2}$ Department of Hematology and Medical Oncology, Winship Cancer Institute of Emory University, 1365 Clifton Rd, Atlanta, GA, USA

Full list of author information is available at the end of the article
}

(c) The Author(s). 2019 Open Access This article is distributed under the terms of the Creative Commons Attribution 4.0 International License (http://creativecommons.org/licenses/by/4.0/), which permits unrestricted use, distribution, and reproduction in any medium, provided you give appropriate credit to the original author(s) and the source, provide a link to the Creative Commons license, and indicate if changes were made. The Creative Commons Public Domain Dedication waiver (http://creativecommons.org/publicdomain/zero/1.0/) applies to the data made available in this article, unless otherwise stated. 


\section{Background}

The emergence of immunotherapy (IO) has transformed the clinical landscape for the treatment of patients with advanced cancers of various histologies [1-5]. As of July 2018, the US Food and Drug Administration (FDA) has approved six immune checkpoint blockers (ICB) for advanced cancer patients. These agents target CTLA-4 (ipilimumab), PD-1 (nivolumab, pembrolizumab), or PD-L1 (atezolizumab, avelumab, and durvalumab) and are used as monotherapy as well as in combination with other anticancer drugs [2, 6-8]. These agents have a more favorable toxicity profile than chemotherapy or targeted therapies and offer the promise of durable clinical benefit, albeit only for a minority of patients [9-13].

As the list of IO options continues to expand [14], selecting the appropriate patients to receive IO represents a critical area of research. Biomarkers of response previously explored include angiopoietin-2 (ANGPT2) in melanoma and polybromo-1 (PBRM1) and polybromo-associated barrier-to-autointegration factor (PBAF) in renal cell carcinoma (RCC) $[6,15]$. In lung cancer, bladder cancer, and RCC, PDL1 expression has been associated with response to ICB [16-19]. Additionally, in lung cancer, tumor mutational burden has been investigated as a potential biomarker for responsiveness to IO-based therapies [20, 21]. In breast cancer, levels of tumor-infiltrating lymphocytes may be prognostic [22, 23]. The identification of a uniform prognostic and predictive biomarker of response to IO across various cancer types remains an unmet need in oncology.

Royal Marsden Hospital (RMH) risk scoring, which incorporates albumin $<3.5 \mathrm{~g} / \mathrm{dL}$, lactate dehydrogenase $>$ the upper limit of normal, and $>$ two sites of metastasis, has been shown to accurately predict survival in patients treated on phase 1 clinical trials across various cancer types [24-26]. While the RMH scoring system predicts that the number of metastatic sites affects clinical outcomes, investigation into differential prognosis between specific metastatic sites in IO therapy is lacking.

Previous studies have established that prognosis for patients with liver metastasis is poor in those with primary colorectal, bladder, and breast cancer [27-31]. Based on the literature that liver metastases point to a worse prognosis in various cancers, we hypothesized that the specific sites of metastatic disease may affect survival in patients enrolled onto IO-based phase 1 clinical trials. In this study, we investigated the association between sites of metastatic disease of various primary histologies and clinical outcomes in patients enrolled on IO-based phase 1 clinical trials.

\section{Methods}

We retrospectively reviewed the electronic medical records of 90 patients with advanced cancer treated on IO-based phase 1 clinical trials between 2009 and 2017 at the Winship
Table 1 Baseline Characteristics and Demographics of Patients

\begin{tabular}{|c|c|}
\hline & $n(\%)$ \\
\hline \multicolumn{2}{|l|}{ Gender } \\
\hline Male & $53(58.9)$ \\
\hline Female & $37(41.1)$ \\
\hline \multicolumn{2}{|l|}{ Race } \\
\hline White & $70(77.8)$ \\
\hline Black & $16(17.8)$ \\
\hline Asian/Unknown & $4(4.4)$ \\
\hline \multicolumn{2}{|l|}{ Histology } \\
\hline Melanoma & $30(33.3)$ \\
\hline Gastrointestinal & $20(22.2)$ \\
\hline Lung, Head \& Neck & $18(20.0)$ \\
\hline Breast & $11(12.2)$ \\
\hline Gynecological cancers & $3(3.3)$ \\
\hline Genitourinary cancers & $3(3.3)$ \\
\hline Others & $5(5.6)$ \\
\hline \multicolumn{2}{|l|}{ Number of metastatic sites } \\
\hline 1 & $24(26.7)$ \\
\hline 2 & $33(36.7)$ \\
\hline $3+$ & $33(36.7)$ \\
\hline \multicolumn{2}{|l|}{ Sites of metastases } \\
\hline Lymph node & $58(64.4)$ \\
\hline Liver & $40(44.4)$ \\
\hline Lung & $37(41.1)$ \\
\hline Bone & $24(26.7)$ \\
\hline Brain & $8(8.9)$ \\
\hline \multicolumn{2}{|l|}{ ECOG PS } \\
\hline 0 & $34(38.2)$ \\
\hline 1 & $55(61.8)$ \\
\hline \multicolumn{2}{|l|}{ RMH Risk Group } \\
\hline Good & $71(80.7)$ \\
\hline Poor & $17(19.3)$ \\
\hline \multicolumn{2}{|l|}{ Checkpoint Indication } \\
\hline Yes & $49(54.4)$ \\
\hline No & $41(45.6)$ \\
\hline \multicolumn{2}{|l|}{ Treatment Regimen } \\
\hline Anti-PD-L1 Monotherapy & $25(27.8)$ \\
\hline FDA-approved IO + Experimental IO & $46(51.1)$ \\
\hline Experimental IO Monotherapy & $19(21.1)$ \\
\hline \multicolumn{2}{|c|}{ Number of prior systemic therapies in the metastatic setting } \\
\hline $0-1$ & $28(31.1)$ \\
\hline $2+$ & $62(68.9)$ \\
\hline \multicolumn{2}{|l|}{ Prior treatment with ICB } \\
\hline Yes & $27(30.0)$ \\
\hline No & $63(70.0)$ \\
\hline
\end{tabular}

ECOG PS Eastern Cooperative Oncology Group performance status, $R M H$ Royal Marsden Hospital, IO Immunotherapy, PD-L1 Programmed death ligand 1, ICB Immune checkpoint blocker 
Table $\mathbf{2}$ UVA of number of metastases with clinical outcome

\begin{tabular}{|c|c|c|c|c|c|c|}
\hline \multirow[b]{2}{*}{ Number of Metastases } & \multicolumn{2}{|l|}{ OS } & \multicolumn{2}{|l|}{ PFS } & \multicolumn{2}{|l|}{ CB } \\
\hline & $\mathrm{HR}(\mathrm{Cl})$ & $p$-value & $\mathrm{HR}(\mathrm{Cl})$ & $p$-value & $\mathrm{OR}(\mathrm{Cl})$ & $p$-value \\
\hline $1(n=24)$ & $0.47(0.22-1.01)$ & 0.054 & $0.60(0.35-1.05)$ & 0.072 & $4.37(1.40-13.64)$ & $0.011^{*}$ \\
\hline $2(n=33)$ & $0.39(0.20-0.78)$ & $0.007^{*}$ & $0.45(0.27-0.77)$ & $0.003^{*}$ & $4.24(1.48-12.17)$ & $0.007^{*}$ \\
\hline $3+(n=33)$ & - & - & - & - & - & - \\
\hline
\end{tabular}

UVA Univariate analysis, OS overall survival, PFS progression-free survival, $C B$ clinical benefit, HR Hazard Ratio, $C I$ Confidence Interval, OR Odds Ratio

*statistical significance at alpha $<0.05$

Cancer Institute of Emory University. Data collected from electronic medical records included: demographic information, medication allergies, Eastern Cooperative Oncology Group (ECOG) performance status (PS), histology, number and site of distant metastases, number and type of prior lines of systemic therapy, prior treatment with ICB, best response to IO on trial, date of radiographic or clinical progression, immune-related adverse events, date of death or last follow-up, and RMH risk factors. Response to treatment was determined by using Response Evaluation Criteria in Solid Tumor version 1.1 by centralized review. The sites of distant metastases that were collected from review of clinic notes and baseline radiology reports included brain, lung, liver, lymph node, and bone.

This data review and analysis was approved by the Emory University Institutional Review Board (IRB), and waiver of consent was granted due to the retrospective nature of this study. All patients provided written informed consent for the phase 1 clinical trial to which they were enrolled, which were also reviewed and approved by the Emory University IRB.

\section{Statistical analysis}

Clinical outcomes were measured using three variables: overall survival (OS), progression-free survival (PFS), and clinical benefit (CB). OS and PFS were measured from the first dose of IO to date of death and clinical or radiographic progression, respectively. For patients who were referred to hospice but did not have confirmed dates of death, date of hospice referral was used in place of date of death. In this cohort, 54 patients had confirmed dates of death, while 9 patients had a documented date of hospice referral without a confirmed date of death. Clinical benefit (CB) was defined as a best response of complete response (CR), partial response $(\mathrm{PR})$, or stable disease (SD) for at least one restaging scan. Median duration of SD for patients in this cohort was 6.7 weeks, with a range of 3.3 to 70.6 weeks. Progressive disease (PD) was defined as a patient coming off trial for declining performance status due to clinical progression.

Statistical analysis was conducted using SAS Version 9.4 and SAS macros developed by the Biostatistics and Bioinformatics Shared Resource at Winship Cancer Institute [32]. The significance level was set at $p<0.05$. The univariate association (UVA) with different sites of metastasis of each covariate used the chi-square test or Fisher's exact for categorical covariates and ANOVA for numerical covariates. The Multivariate analysis (MVA) of OS or PFS was tested by proportional hazard model, with hazard ratio (HR) and its 95\% confidence interval (CI) being reported. The multivariable model was built by controlling for age, gender, allergies, race, the patient's primary histology, ECOG PS, RMH risk group, history of diabetes, prior IO, number of prior therapies, and number of distant metastatic sites following by a backward selection

Table 3 UVA of sites of metastases with clinical outcome

\begin{tabular}{|c|c|c|c|c|c|c|}
\hline \multirow[t]{2}{*}{ Site of Metastasis } & \multicolumn{2}{|l|}{ OS } & \multicolumn{2}{|l|}{ PFS } & \multicolumn{2}{|l|}{$C B$} \\
\hline & $\mathrm{HR}(\mathrm{Cl})$ & $p$-value & $\mathrm{HR}(\mathrm{Cl})$ & $p$-value & $\mathrm{OR}(\mathrm{Cl})$ & $p$-value \\
\hline No lymph node metastases $(n=32)$ & $1.42(0.79-2.54)$ & 0.244 & $1.16(0.74-1.83)$ & 0.524 & $0.73(0.31-1.76)$ & 0.486 \\
\hline Lymph node metastases $(n=58)$ & - & - & - & - & - & - \\
\hline No bone metastases $(n=66)$ & $0.61(0.32-1.17)$ & 0.135 & $0.80(0.48-1.32)$ & 0.376 & $2.00(0.75-5.31)$ & 0.164 \\
\hline Bone metastases $(n=24)$ & - & - & - & - & - & - \\
\hline No liver metastases $(n=50)$ & $0.42(0.23-0.78)$ & $0.006^{*}$ & $0.60(0.39-0.93)$ & $0.024^{*}$ & $2.64(1.11-6.28)$ & $0.028^{*}$ \\
\hline Liver metastases $(n=40)$ & - & - & - & - & - & - \\
\hline No brain metastases $(n=82)$ & $0.69(0.29-1.64)$ & 0.406 & $0.86(0.40-1.88)$ & 0.712 & $1.44(0.32-6.42)$ & 0.633 \\
\hline Brain metastases & - & - & - & - & - & - \\
\hline No lung $(n=53)$ & $1.02(0.57-1.82)$ & 0.944 & $1.20(0.76-1.87)$ & 0.433 & $1.17(0.50-2.73)$ & 0.713 \\
\hline Lung metastases $(n=37)$ & - & - & - & - & - & - \\
\hline
\end{tabular}

UVA Univariate analysis, OS overall survival, PFS progression-free survival, CB clinical benefit, HR Hazard Ratio, Cl Confidence Interval, OR Odds Ratio *statistical significance at alpha $<0.05$ 
Table 4 MVAt of liver metastases with clinical outcome

\begin{tabular}{|c|c|c|c|c|c|c|}
\hline & \multicolumn{2}{|l|}{ OS } & \multicolumn{2}{|l|}{ PFS } & \multicolumn{2}{|l|}{ CB } \\
\hline & $\mathrm{HR}(\mathrm{Cl})$ & $p$-value & $\mathrm{HR}(\mathrm{Cl})$ & $p$-value & $\mathrm{OR}(\mathrm{Cl})$ & $p$-value \\
\hline \multirow[t]{2}{*}{ No liver metastases $(n=50)$} & $0.38(0.17-0.84)$ & $0.017^{*}$ & $0.70(0.41-1.19)$ & 0.188 & $1.42(0.39-5.21)$ & 0.597 \\
\hline & \multicolumn{2}{|c|}{$\begin{array}{l}\text { Median: } 21.9 \text { months } 12 \text { month } \\
\text { survival: } 60 \%\end{array}$} & \multicolumn{2}{|c|}{$\begin{array}{l}\text { Median: } 3.6 \text { months } 12 \text { month } \\
\text { survival: } 13 \%\end{array}$} & Rate: 56\% (0 CR, 6 PR, 22 SD, 17 PD, 5 NE) & $0.026^{*}$ \\
\hline Liver metastases $(n=40)$ & \multicolumn{2}{|c|}{$\begin{array}{l}\text { Median: } 8.1 \text { months } 12 \text { month } \\
\text { survival: } 19 \%\end{array}$} & \multicolumn{2}{|c|}{$\begin{array}{l}\text { Median: } 1.8 \text { months } 12 \text { month } \\
\text { survival: } 5 \%\end{array}$} & Rate: 33\% (1 CR, 1 PR, 11 SD, 24 PD, 3 NE) & - \\
\hline
\end{tabular}

MVA Multivariate analysis, OS overall survival, PFS progression-free survival, $C B$ clinical benefit

† Covariates considered in MVA initially include age, gender, ECOG PS, prior IO, number of prior therapies, RMH risk group, race, number of metastatic sites and primary histology. Backward selection procedure was implemented by removal criterial of $p>0.05$. The final controlled variables are primary histology and RMH risk group for OS and PFS and primary histology, race, and number of prior therapies for CB. MVA Multivariate analysis, OS overall survival, PFS progression-free survival, $C B$ clinical benefit, $H R$ Hazard Ratio, $C l$ Confidence Interval, OR Odds Ratio

*statistical significance at alpha $<0.05$ by Chi-square test

procedure with a removal criterial of alpha $>0.05$. Similar strategy was used to fit logistic regression model for CB.

\section{Results}

Patient demographic information and disease characteristics are presented in Table 1 . The majority of patients (58.9\%) in this retrospective cohort of 90 patients were men. The most common histology was melanoma (33.3\%), followed by gastrointestinal (GI) cancers (22.2\%), and lung and head \& neck cancers (20.0\%). More than half of the patients $(n=46,51.1 \%)$ received an FDA-approved ICB combined with an experimental IO agent, 27.8\% $(n=25)$ of patients received anti-PD-L1 monotherapy, and $21.1 \%(n=$ 19) received an experimental IO agent as monotherapy. Most patients $(n=62,68.9 \%)$ had received two or more prior lines of systemic treatment before receiving IO on trial; 27 patients $(30.0 \%)$ received prior ICB. The majority of patients $(80.7 \%)$ were $\mathrm{RMH}$ good risk while 17 patients were $\mathrm{RMH}$ poor risk at the start of IO.

Most patients (73.3\%) had more than one site of distant metastasis. Sites of metastasis recorded were lymph nodes $(n=58)$, liver $(n=40)$, lung $(n=37)$, bone $(n=24)$ and brain $(n=8)$. Metastasis to each of these sites was analyzed for association with OS, PFS, and CB.

UVA of total number of and sites of metastatic disease with clinical outcome are provided in Tables 2 and 3, respectively. The presence of liver metastasis was significantly associated with shorter OS, PFS, and lower rate of CB in UVA (all $p<0.03$ ). Other sites of metastatic disease were not significant in UVA. Therefore, we built an MVA using liver metastases as a risk factor, provided in Table 4 . In MVA, patients with liver metastases had significantly

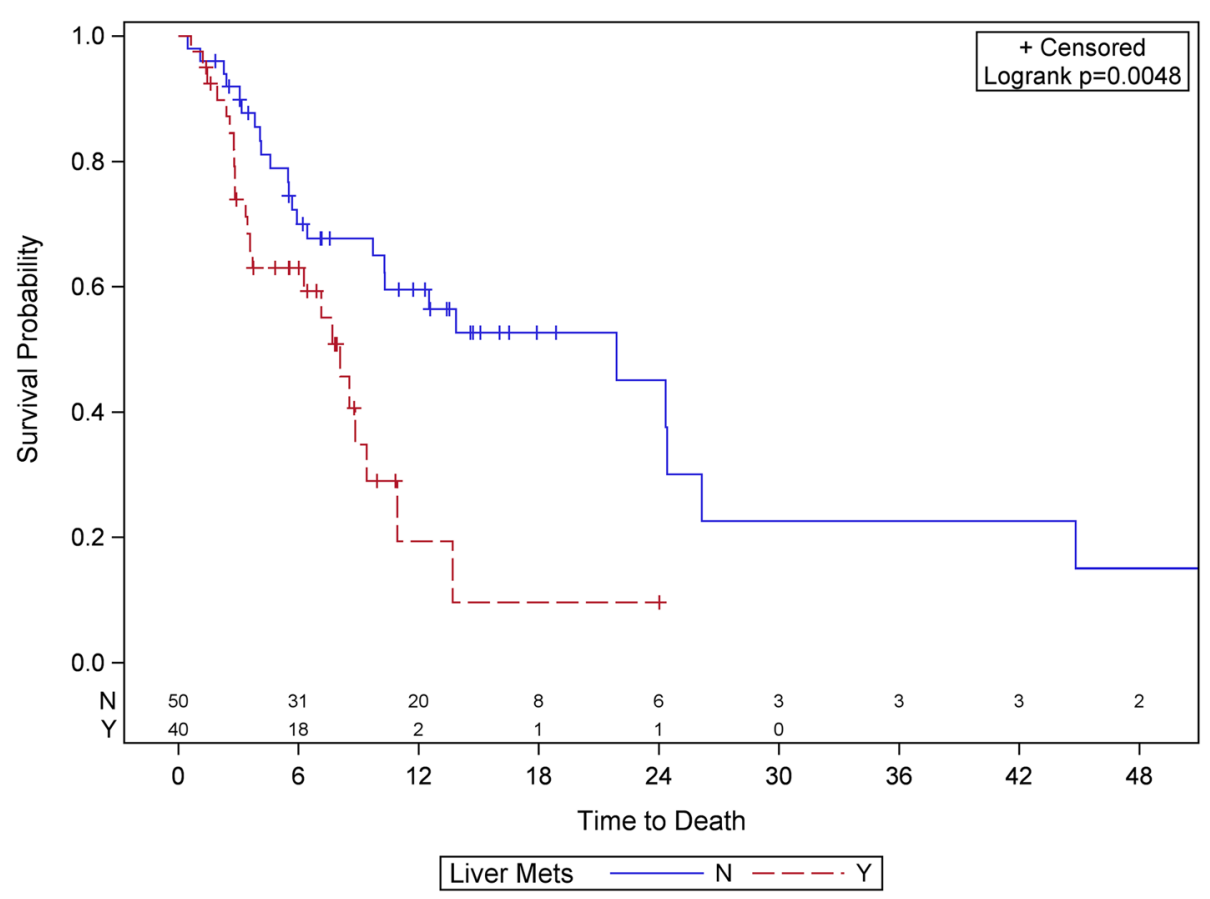

Fig. 1 Kaplan-Meier plot of overall survival (OS) stratified by presence of liver metastases 


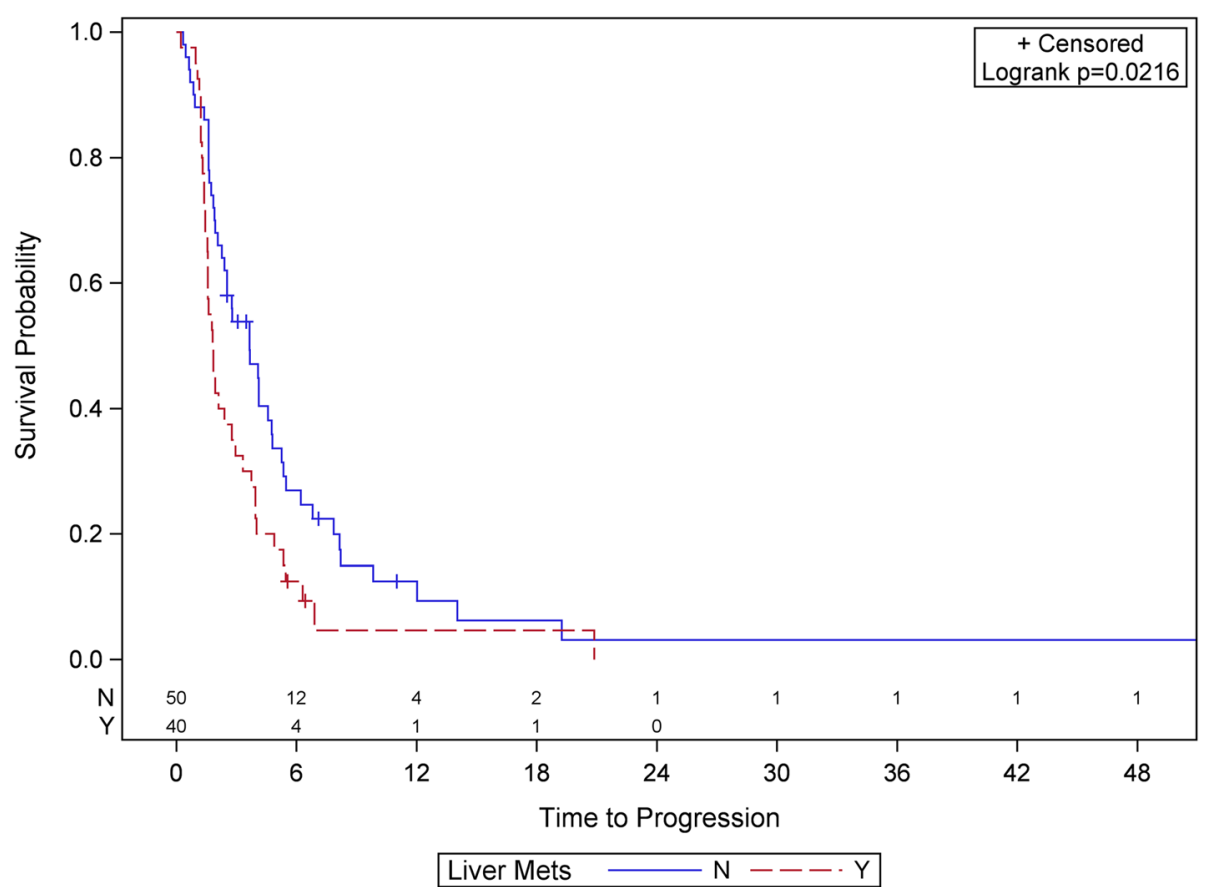

Fig. 2 Kaplan-Meier plot of progression-free survival (PFS) stratified by presence of liver metastases

shorter OS (HR: 0.38, CI: 0.17-0.84, $p=0.017)$ and trended towards having shorter PFS (HR: 0.70, CI: 0.41-1.19, $p=$ 0.188 ), regardless of patients' primary histologies. The median OS was substantially longer for patients without liver metastases (21.9 vs. 8.1 months, $p=0.0048$ ). The KaplanMeier plot of the association between liver metastases and OS and PFS are shown in Fig. 1 and Fig. 2, respectively.

Patients with reported liver metastasis most commonly had primary GI tumors (47.5\%); non-GI tumors included melanoma (27.5\%), lung and head \& neck (10\%), breast (7.5\%), and gynecologic (2.5\%). Patients without reported liver metastasis most commonly had primary melanoma (38\%) and lung and head \& neck tumors (28\%). Of the patients with liver metastases, $71.8 \%$ were $\mathrm{RMH}$ good risk at the start of IO. Most patients with liver metastases $(72.5 \%)$ had received two or more lines of systemic therapy prior to treatment with IO. Patients with metastatic disease in the liver were more likely to have a greater total number of sites of metastatic disease. One half $(50 \%)$ of the patients with liver metastases had a total of three or more distant metastases while only $26 \%$ of patients without liver metastases had three or more distant metastatic sites.

\section{Discussion}

In this study, we demonstrated that metastasis to the liver is associated with worse clinical outcomes in advanced stage cancer patients treated on IO-based phase 1 clinical trials. Regardless of tumor histology, patients in this cohort with documented metastasis to the liver had shorter OS and PFS and a lower rate of CB. The results from this study build upon previous studies that have explored the predictive value of metastatic sites in cancers treated with chemotherapy, particularly in breast, bladder, and colon cancer [27-31, 33]. In this study we assessed different sites of metastatic disease and clinical outcomes in patients treated with IO-based regimens as part of phase 1 clinical trials, which has not been investigated previously. The results support the Pires da Silva et al. study findings that in melanoma patients who receive combination immunotherapy, different metastatic sites exhibit different effects on survival, and patients with liver metastases experience inferior clinical responses [34]. Our cohort of patients receiving IObased therapy in phase 1 clinical trials is a unique population. The cohort includes patients with several different primary cancer types rather than just one. Furthermore, patients enrolled onto phase 1 clinical trials receive novel IO agents, which is another reason to investigate this cohort of patients.

Evidence suggests that primary tumor histology influences prognosis for patients with metastasis to the liver who are treated with chemotherapy. Jaffe et al. (1968) found that primary tumor site influences prognosis for patients with hepatic metastases [35]. Furthermore, Soni et al. (2015) found that subtypes of breast cancer differ in their metastatic behavior [36]. The results of our study, however, suggest that for patients on IO-based phase 1 clinical trials, regardless of primary tumor site, liver metastases are a poor prognostic indicator. This may be explained biologically by the liver's immuno-regulatory behavior [37]. The liver, 
notably located between the genitourinary circulation and systemic circulation, functions as a secondary lymphoid organ. It contains a high density of natural killer T-cells as well as T-regulatory cells $[37,38]$. Therefore, metastases to the liver may interfere with the immune-regulatory behavior of the organ, which in turn affects the response of cancer patients on IO. The mechanism by which this occurs should be explored further.

The presence of metastatic disease in the liver has been established as a poor predictive factor for patients receiving chemotherapy-based treatment and has thus merited different or more aggressive treatment for patients with liver metastases. Previous studies have found that patients with breast and colorectal cancer with metastases to the liver may receive clinical benefit from liver resection [39-43]. Given these previous findings in cohorts treated with chemotherapy, patients with solitary liver metastases may benefit from liver resection prior to starting IO. However, many patients in our study cohort with advanced stage cancers of various primary tumor histologies had multiple liver metastases, making liver resection not clinically appropriate. Priestman and Hanham (1972) found that combination chemotherapy produces longer overall survival rates than single chemotherapy in treating patients with breast or colorectal cancer with liver metastases [44]. Using these results in chemotherapy-based treatment as a model, clinical outcomes for patients on IO-based therapy may improve with combination chemotherapy or targeted therapy to the liver prior to or in addition to IO. Additionally, radiation therapy to the liver prior to initiating IO could improve clinical outcomes in patients with hepatic metastases, as per the abscopal effect [45-47].

Our analysis has limitations to note. This is a retrospective study, which is inherently subject to selection bias. We attempted to mitigate this bias by including all patients who received at least one dose of IO on a phase 1 clinical trial at our institution. Due to our lenient inclusion criteria, the patient population was very heterogeneous in primary tumor histology and in type of IO received. We accounted for this by controlling for primary tumor histology and other baseline disease characteristics. Though the size of our patient cohort may limit the impact of this study, given our lenient inclusion criteria, the study cohort was the largest cohort of patients receiving immunotherapy as part of phase 1 clinical trials at our institution. Additionally, only the five most common sites of metastasis were captured and analyzed independently. We did not differentiate between isolated metastases to the liver versus widespread metastatic disease. There were very few patients with brain metastases, so the predictive value of brain metastases could not be adequately analyzed. Finally, patients enrolled onto phase 1 clinical trials likely have further advanced disease than patients who receive immunotherapy in the first or second line, which limits the generalizability of this study.

\section{Conclusions}

Liver metastases are a poor predictive factor in this cohort of patients treated on IO-based phase 1 clinical trials. Patients in the retrospective cohort with hepatic metastases had shorter OS, PFS and lower rate of $\mathrm{CB}$. If these findings are validated in a larger study, this baseline disease characteristic may warrant consideration in updated prognostic models for stratification of patients enrolled onto IO-based phase 1 clinical trials. The presence of liver metastases should not preclude patients from enrolling onto phase 1 trials. Rather, the results of this study reveal an important area for improvement in IO-based therapies for advanced stage cancer patients with hepatic metastases. Further advancements in treating these patients are needed. The detection of liver metastasis in advanced stage cancer patients may be especially useful in determining whether these patients should receive novel combination therapy or should receive liver-targeted therapy prior to or in combination with IO, given the unique microenvironment around metastatic tumors in the liver.

\section{Abbreviations \\ CB: Clinical benefit; Cl: Confidence interval; CR: Complete response; CTLA- 4: Cytotoxic T-lymphocyte associated protein 4; ECOG: Eastern Cooperative Oncology Group; FDA: Food and Drug Administration; Gl: Gastrointestinal; HR: Hazard ratio; ICB: Immune checkpoint blocker; IO: Immunotherapy; MVA: Multivariate analysis; OS: Overall survival; PD-1: Programmed cell death protein 1; PD-L1: Programmed death ligand 1; PFS: Progression-free survival; PR: Partial response; PS: Performance status; RCC: Renal cell carcinoma; RMH: Royal Marsden Hospital; SD: Stable disease; UVA: Univariate analysis}

\section{Acknowledgments}

The content is solely the responsibility of the authors and does not necessarily represent the official views of the National Institutes of Health. Part of data in this study was presented at the ESMO 2018 Congress in Munich, Germany.

\section{Authors' contributions}

$M A B$ was involved in the identification and selection of patients, construction of the database, caring for the patients included in the study, study design and methodology, interpretation and analysis of study results, and the writing of the manuscript. JMS was involved in data acquisition, interpretation and analysis of study results, writing the manuscript, and administrative support. DJM was involved in construction of the database, data acquisition, interpretation and analysis of study results, writing of the manuscript, and administrative support. YL was involved in the design and methodology of the study, all statistical analysis, interpretation and analysis of study results, and writing of the manuscript. MAB and RDH supervised the study. CL, HC, MA, HK, BCC, WLS, OBA, CES, CW, DHL, RK, VAM, BE, SSR, TKO were involved in the care of the patients in this study, interpretation and analysis of study results, and editing the manuscript. All authors reviewed and accepted the final version of the manuscript.

\section{Funding}

Research reported in this publication was supported in part by the Biostatistics and Bioinformatics Shared Resource of the Winship Cancer Institute of Emory University and $\mathrm{NIH} / \mathrm{NCl}$ under award number P30CA138292. The content is solely the work and responsibility of the 
authors and does not necessarily represent the official views of the National Institutes of Health.

\section{Availability of data and materials}

The datasets used and/or analyzed during the current study are available from the corresponding author on reasonable request.

\section{Ethics approval and consent to participate}

This data review and analysis was approved by the Emory University Institutional Review Board (IRB), and waiver of consent was granted due to the retrospective nature of this study. All patients provided written informed consent for the phase 1 clinical trial to which they were enrolled, also reviewed and approved by the Emory University IRB.

\section{Consent for publication}

Not applicable.

\section{Competing interests}

BCC has a consulting/advisory role with Astellas Medivation, Pfizer, and Blue Earth Diagnostics and receives travel accommodations from Bristol-Myers Squibb. WLS receives research funding from ArQule and Lilly. RP has a consulting/advisory role with Natera and AstraZeneca and receives travel accommodations from Genentech/Roche, Takeda, Novartis, and Clovis Oncology. She also receives research funding from Bristol-Myers Squibb. CW receives honorarium from BioTheranostics and research funding from Amgen, BristolMyers Squibb, Vaccinex, and Boston Biomedical. RRK has a consulting/advisory role with Bristol-Myers Squibb, Novartis, and Array BioPharma. She also receives honorarium from Bristol-Myers Squibb and research funding from Merck. BFE has a consulting/advisory role with Merrimack, BTG, Bayer, Loxo, and RTI Health Solutions. He is a member of the speakers' bureau of Lexicon and Bristol-Myers Squibb. He also receives honorarium from Lexicon, RTI Health Solutions, and Bayer and received research funding from Taiho Pharmaceutical, Bristol-Myers Squibb, Boston Biomedical, Cleave Biosciences, Genentech, AVEO, Pfizer, Novartis, Hoosier Cancer Research Network, Five Prime Therapeutics, PPD Inc., Merck, and ICON Clinical Research. SSR has a consulting/advisory role with Amgen, Boehringer Ingelheim, Celgene, Genetech/Roche, Lilly/ImClone, Bristol-Myers Squibb, AstraZeneca, Abbvie, Merck, and Takeda and receives travel accommodations from EMD Serono, Pfizer, and AstraZeneca. TKO has a consulting/advisory role with Novartis, BristolMyers Squibb, and Medlmmune. MAB has a consulting/advisory role with Exelixis, Sanofi and Nektar and receives research funding from Bayer, BristolMyers Squibb, Genentech/Roche, Incyte, Nektar, AstraZeneca, Tricon Pharmaceuticals, Peleton, and Pfizer.

\section{Author details}

${ }^{1}$ Department of Hematology and Medical Oncology, Emory University School of Medicine, Atlanta, GA, USA. ²Department of Hematology and Medical Oncology, Winship Cancer Institute of Emory University, 1365 Clifton Rd, Atlanta, GA, USA. ${ }^{3}$ Departments of Biostatistics and Bioinformatics, Emory University, 1518 Clifton Rd, Atlanta, GA, USA. ${ }^{4}$ Department of Urology, Emory University, 5673 Peachtree, Dunwoody Rd, Atlanta, GA, USA. ${ }^{5}$ Department of Pharmacology, Emory University School of Medicine, 1365 Clifton Rd, Atlanta, GA, USA.

Received: 22 September 2018 Accepted: 22 August 2019 Published online: 29 August 2019

\section{References}

1. Emens LA, Kok M, Ojalvo LS. Targeting the programmed cell death-1 pathway in breast and ovarian cancer. Curr Opin Obstet Gynecol. 2016; 28(2):142-7.

2. Chae YK, Arya A, lams W, Cruz MR, Chandra S, Choi J, et al. Current landscape and future of dual anti-CTLA4 and PD-1/PD-L1 blockade immunotherapy in cancer; lessons learned from clinical trials with melanoma and non-small cell lung cancer (NSCLC). J Immunother Cancer. 2018;6(1):39.

3. La-Beck NM, Jean GW, Huynh C, Alzghari SK, Lowe DB. Immune checkpoint inhibitors: new insights and current place in Cancer therapy. Pharmacotherapy. 2015;35(10):963-76.

4. Balar AV, Galsky MD, Rosenberg JE, Powles T, Petrylak DP, Bellmunt J, et al. Atezolizumab as first-line treatment in cisplatin-ineligible patients with locally advanced and metastatic urothelial carcinoma: a single-arm, multicentre, phase 2 trial. Lancet. 2017;389(10064):67-76.

5. Motzer RJ, Escudier B, McDermott DF, George S, Hammers HJ, Srinivas S, et al. Nivolumab versus Everolimus in advanced renal-cell carcinoma. N Engl J Med. 2015;373(19):1803-13

6. Miao D, Margolis CA, Gao W, Voss MH, Li W, Martini DJ, et al. Genomic correlates of response to immune checkpoint therapies in clear cell renal cell carcinoma. Science. 2018;359(6377):801-6.

7. Chism DD. Urothelial carcinoma of the bladder and the rise of immunotherapy. J Natl Compr Cancer Netw. 2017;15(10):1277-84.

8. Das R, Verma R, Sznol M, Boddupalli CS, Gettinger SN, Kluger H, et al. Combination therapy with anti-CTLA-4 and anti-PD-1 leads to distinct immunologic changes in vivo. J Immunol. 2015;194(3):950-9.

9. Michot JM, Bigenwald C, Champiat S, Collins M, Carbonnel F, Postel-Vinay S, et al. Immune-related adverse events with immune checkpoint blockade: a comprehensive review. Eur J Cancer. 2016;54:139-48.

10. Tay R, Prelaj A, Califano R. Immune checkpoint blockade for advanced nonsmall cell lung cancer: challenging clinical scenarios. J Thorac Dis. 2018; 10(Suppl 13):S1494-S502.

11. Wang C, Yu X, Wang W. A meta-analysis of efficacy and safety of antibodies targeting PD-1/PD-L1 in treatment of advanced nonsmall cell lung cancer. Medicine (Baltimore). 2016;95(52):e5539.

12. McDermott D, Lebbe C, Hodi FS, Maio M, Weber JS, Wolchok JD, et al. Durable benefit and the potential for long-term survival with immunotherapy in advanced melanoma. Cancer Treat Rev. 2014;40(9):1056-64.

13. Martini DJ, Hamieh L, McKay RR, Harshman LC, Brandao R, Norton CK, et al. Durable clinical benefit in metastatic renal cell carcinoma patients who discontinue PD-1/PD-L1 therapy for immune-related adverse events. Cancer Immunol Res. 2018;6(4):402-8.

14. ClinicalTrials.gov. [Available from: https:/clinicaltrials.gov/. Accessed 10 Sept 2018.

15. Wu X, Giobbie-Hurder A, Liao X, Connelly C, Connolly EM, Li J, et al. Angiopoietin-2 as a biomarker and target for immune checkpoint therapy. Cancer Immunol Res. 2017;5(1):17-28.

16. Mu CY, Huang JA, Chen Y, Chen C, Zhang XG. High expression of PD-L1 in lung cancer may contribute to poor prognosis and tumor cells immune escape through suppressing tumor infiltrating dendritic cells maturation. Med Oncol. 2011;28(3):682-8.

17. Thompson RH, Gillett MD, Cheville JC, Lohse CM, Dong H, Webster WS, et al. Costimulatory B7-H1 in renal cell carcinoma patients: Indicator of tumor aggressiveness and potential therapeutic target. Proc Natl Acad Sci U S A. 2004;101(49):17174-9.

18. Huang $Y$, Zhang SD, McCrudden $C$, Chan KW, Lin $Y$, Kwok HF. The prognostic significance of PD-L1 in bladder cancer. Oncol Rep. 2015;33(6):3075-84.

19. Herbst RS, Soria JC, Kowanetz M, Fine GD, Hamid O, Gordon MS, et al. Predictive correlates of response to the anti-PD-L1 antibody MPDL3280A in cancer patients. Nature. 2014;515(7528):563-7.

20. Hellmann MD, Ciuleanu TE, Pluzanski A, Lee JS, Otterson GA, AudigierValette C, et al. Nivolumab plus Ipilimumab in lung Cancer with a high tumor mutational burden. N Engl J Med. 2018;378(22):2093-104.

21. Ahmadzada T, Kao S, Reid G, Boyer M, Mahar A, Cooper WA. An Update on Predictive Biomarkers for Treatment Selection in Non-Small Cell Lung Cancer. J Clin Med. 2018;7(6):153.

22. Hendry S, Salgado R, Gevaert T, Russell PA, John T, Thapa B, et al. Assessing Tumor-Infiltrating Lymphocytes in Solid Tumors: A Practical Review for Pathologists and Proposal for a Standardized Method from the International Immuno-Oncology Biomarkers Working Group: Part 2: TILs in Melanoma, Gastrointestinal Tract Carcinomas, Non-Small Cell Lung Carcinoma and Mesothelioma, Endometrial and Ovarian Carcinomas, Squamous Cell Carcinoma of the Head and Neck, Genitourinary Carcinomas, and Primary Brain Tumors. Adv Anat Pathol. 2017;24(6):311-35.

23. Salgado R, Denkert C, Demaria S, Sirtaine N, Klauschen F, Pruneri G, et al. The evaluation of tumor-infiltrating lymphocytes (TILS) in breast cancer: recommendations by an international TLLs working group 2014. Ann Oncol. 2015; 26(2):259-71.

24. Arkenau HT, Olmos D, Ang JE, de Bono J, Judson I, Kaye S. Clinical outcome and prognostic factors for patients treated within the context of a phase I study: the Royal Marsden Hospital experience. Br J Cancer. 2008;98(6):1029-33.

25. Garrido-Laguna I, Janku F, Vaklavas C, Falchook GS, Fu S, Hong DS, et al. Validation of the Royal Marsden Hospital prognostic score in patients treated in the phase I clinical trials program at the MD Anderson Cancer Center. Cancer. 2012;118(5):1422-8. 
26. Arkenau HT, Barriuso J, Olmos D, Ang JE, de Bono J, Judson I, et al. Prospective validation of a prognostic score to improve patient selection for oncology phase I trials. J Clin Oncol. 2009;27(16):2692-6.

27. Wyld L, Gutteridge E, Pinder SE, James JJ, Chan SY, Cheung KL, et al. Prognostic factors for patients with hepatic metastases from breast cancer. $\mathrm{Br} J \mathrm{Cancer}$. 2003:89(2):284-90.

28. Ma R, Feng $Y$, Lin $S$, Chen J, Lin H, Liang $X$, et al. Mechanisms involved in breast cancer liver metastasis. J Transl Med. 2015;13:64.

29. Ye LC, Liu TS, Ren L, Wei Y, Zhu DX, Zai SY, et al. Randomized controlled trial of cetuximab plus chemotherapy for patients with KRAS wild-type unresectable colorectal liver-limited metastases. J Clin Oncol. 2013;31(16):1931-8.

30. Zarour LR, Anand S, Billingsley KG, Bisson WH, Cercek A, Clarke MF, et al. Colorectal Cancer liver metastasis: evolving paradigms and future directions. Cell Mol Gastroenterol Hepatol. 2017;3(2):163-73.

31. Rosenberg JE, Hoffman-Censits J, Powles T, van der Heijden MS, Balar AV, Necchi A, et al. Atezolizumab in patients with locally advanced and metastatic urothelial carcinoma who have progressed following treatment with platinum-based chemotherapy: a single-arm, multicentre, phase 2 trial, Lancet. 2016;387(10031):1909-20.

32. Mandrekar JN, Mandrekar SJ, Cha SS. Cutpoint Determination Methods in Survival Analysis using SAS. Proceedings of the 28th SAS Users Group International Conference (SUGI). 2003:261:28.

33. Bellmunt J, de Wit R, Vaughn DJ, Fradet $Y$, Lee $J$, Fong $L$, et al. Pembrolizumab as second-line therapy for advanced urothelial carcinoma. N Engl J Med. 2017;376(11):1015-26.

34. Pires da Silva I, Lo S, Gonzalez M, Guminski AD, Long GV, Menzies AM. Distinct patterns of response and toxicity (tox) by sites of metastases (mets) in patients (pts) treated with ipilimumab combined with PD-1 antibodies (ipi+PD1). J Clin Oncol. 2018;36(15):9553.

35. Jaffe BM, Donegan WL, Watson F, Spratt JS Jr. Factors influencing survival in patients with untreated hepatic metastases. Surg Gynecol Obstet. 1968; 127(1):1-11.

36. Soni A, Ren Z, Hameed O, Chanda D, Morgan CJ, Siegal GP, et al. Breast cancer subtypes predispose the site of distant metastases. Am J Clin Pathol. 2015;143(4):471-8

37. Mazzolini G, Ochoa MC, Morales-Kastresana A, Sanmamed MF, Melero I. The liver, liver metastasis and liver cancer: a special case for immunotherapy with cytokines and immunostimulatory monoclonal antibodies. Immunotherapy. 2012;4(11):1081-5.

38. Dolina JS, Braciale TJ, Hahn YS. Liver-primed CD8+ T cells suppress antiviral adaptive immunity through galectin-9-independent T-cell immunoglobulin and mucin 3 engagement of high-mobility group box 1 in mice. Hepatology. 2014;59(4):1351-65.

39. Van Cutsem E, Cervantes A, Adam R, Sobrero A, Van Krieken JH, Aderka D, et al. ESMO consensus guidelines for the management of patients with metastatic colorectal cancer. Ann Oncol. 2016;27(8):1386-422.

40. Hughes KS, Rosenstein RB, Songhorabodi S, Adson MA, Ilstrup DM, Fortner $J G$, et al. Resection of the liver for colorectal carcinoma metastases. A multiinstitutional study of long-term survivors. Dis Colon Rectum. 1988;31(1):1-4.

41. Fong Y, Fortner J, Sun RL, Brennan MF, Blumgart LH. Clinical score for predicting recurrence after hepatic resection for metastatic colorectal cancer: analysis of 1001 consecutive cases. Ann Surg. 1999;230(3):309-18 discussion 18-21.

42. van Walsum GA, de Ridder JA, Verhoef C, Bosscha K, van Gulik TM, Hesselink EJ, et al. Resection of liver metastases in patients with breast cancer: survival and prognostic factors. Eur J Surg Oncol. 2012;38(10):910-7.

43. Maksan SM, Lehnert T, Bastert G, Herfarth C. Curative liver resection for metastatic breast cancer. Eur J Surg Oncol. 2000;26(3):209-12.

44. Priestman TJ, Hanham IW. Results of 27 cases with hepatic metastases treated by combination chemotherapy. Br J Cancer. 1972;26(6):466-72

45. Mole RH. Whole body irradiation; radiobiology or medicine? $\mathrm{Br} J$ Radiol. 1953;26(305):234-41

46. Gong J, Le TQ, Massarelli E, Hendifar AE, Tuli R. Radiation therapy and PD-1/ PD-L1 blockade: the clinical development of an evolving anticancer combination. J Immunother Cancer. 2018;6(1):46.

47. Reynders K, Illidge T, Siva S, Chang JY, De Ruysscher D. The abscopal effect of local radiotherapy: using immunotherapy to make a rare event clinically relevant. Cancer Treat Rev. 2015;41(6):503-10.

\section{Publisher's Note}

Springer Nature remains neutral with regard to jurisdictional claims in published maps and institutional affiliations.

Ready to submit your research? Choose BMC and benefit from:

- fast, convenient online submission

- thorough peer review by experienced researchers in your field

- rapid publication on acceptance

- support for research data, including large and complex data types

- gold Open Access which fosters wider collaboration and increased citations

- maximum visibility for your research: over $100 \mathrm{M}$ website views per year

At BMC, research is always in progress.

Learn more biomedcentral.com/submissions 